\title{
An Integrated Diagnostic Approach for Citrus Exocortis Viroid
}

Chih-Hsu Lin

National Taiwan University

Ting-Hsuan Hung

National Taiwan University

I Hu

National Taiwan University

$\mathrm{Ta}-\mathrm{Hsin} \mathrm{Ku}$

National Taiwan University

Chun-Yi Lin

National Taiwan University

Meng-Ling Wu

Taiwan Forestry Research Institute

Tang-Long Shen ( $\nabla$ shentl@ntu.edu.tw )

National Taiwan University

\section{Research Article}

Keywords: CEVd, bio-index, dot blot hybridization, one-step RT-PCR, real-time RT-PCR

Posted Date: August 10th, 2021

DOI: https://doi.org/10.21203/rs.3.rs-768766/v1

License: (c) (1) This work is licensed under a Creative Commons Attribution 4.0 International License.

Read Full License 


\section{Abstract}

\section{Background}

Citrus exocortis viroid (CEVd) is a circular single-stranded RNA pathogen consists of around 370 nucleotides and leads to a severe disease showing bark scaling symptom on citrus crops, which leads to yield decrease and economic loss. Since the absence of viroid-encoded proteins, methods for CEVd detection mainly counts on bioassays or nucleic acid-base approaches. In order to validate the CEVd disease, here we developed an integrated diagnostic protocol.

\section{Methods}

CEVd transcripts were inoculated onto two susceptible cultivars of Solanum lycopersicum L., cv. Rutgers and cv. Double-Fortune, seedings. After inoculation, total RNAs of the two tomato cultivars were extracted to detect CEVd infection by dot blot hybridization, one-step reverse transcription PCR (one-step RT-PCR) and real-time reverse transcription PCR (real-time RT-PCR). In addition, the symptom development of both cultivars was recorded weekly.

Results

The tomato cultivar Rutgers rather than Double-Fortune or others was selected as a suitable CEVdindicator plant and the bio-index score was established based on epinasty, vein necrosis, leaf size reduction and stunting symptoms. In addition, the isolate of CEVd that collected from citrus field could rapidly and consistently cause the index symptoms on Rutgers. As expected, CEVd could be specifically and sensitively detected in both tomato and citrus plants by dot-blot hybridization and RT-PCR technologies, including one-step RT-PCR and real-time RT-PCR. Furthermore, we found that the levels of CEVd genomic RNA or CEVd derived small RNAs are correlated to symptom severity. Conclusions

In this study, we developed an integrated detection method for CEVd and revealed potential underlying viroid-host interactions.

\section{Background}

As simple as solely bearing a single-stranded, circular, noncoding RNA with a range of 246-401 nucleotides in size, viroids are known the smallest plant pathogens. Given a tiny genome, viroids are difficult to be detected and thereof often neglected. So far, little is known about the importance and pathogenesis of viroids although many economic crops are reportedly susceptible for viroid infection (Daròs, Elena, and Flores, 2006; Ding, 2009; Ding and Itaya, 2007; Ding and Wang, 2009; Flores et al., 2005; Tsagris et al., 2008). Without any coding proteins to provide specific functions and not being protected in a coat protein or an envelope, viroids have gained much interest in recent years to elucidate how a non-coding RNA interacts with host factor(s) to accomplish its replication and pathogenicity, such 
as survival from the cellular RNA degradation machineries, replication in specific subcellular compartments, and trafficking in a plant.

Among Pospiviroidae, seven viroids, including Citrus exocortis viroid (CEVd, genus Pospiviroid), Hop stunt viroid (HSVd, genus Hostuviroid), Citrus bent leaf viroid (CBLVd, genus Apscaviroid), Citrus dwarfing viroid (CDVd, genus Apscaviroid) (former Citrus viroid III, CVd-III), Citrus bark cracking viroid (CBCVd, genus Cocadviroid) (former Citrus viroid IV, CVd-IV), Citrus viroid V (CVd-V, genus Apscaviroid) and Citrus viroid VI (CVd-VI, genus Apscaviroid) (initially named Citrus viroid original sample, CVd-OS (Ito et al., 2001)), are reportedly able to infect citrus (Adams et al., 2016). Among these, Citrus exocortis viroid (CEVd), the causal agent of the exocortis disease of citrus plants (Semancik and Weathers, 1972), leads to a bark shelling or scaling disorder that affects trifoliate orange (Poncirus trifoliata (L.) Raf.), Troyer citrange, Carrizo citrange (Citrus sinensis (L.) Osbeck×Poncirus trifoliata (L.) Raf.) and Rangpur lime (C. limonia Osb.), which are all widely used as root-stocks in commercial orchards (Vernière et al., 2006). Not only citrus species, but also many different plants are reported in field grown herbaceous hosts, including tomato (Solanum lycopersicum L.) (Fagoaga and DuranVila, 1996; Mishra et al., 1991; Verhoeven et al., 2004), eggplant (S. melongena L. cv. Sonja) (Fadda et al., 2003; Fagoaga and DuranVila, 1996; Fagoaga, Pina, and Duran-Vila, 1994), carrot (Daucus carota L.), turnip (Brassica napus L.) (Fagoaga and DuranVila, 1996), broad bean (Vicia faba L.) (Fagoaga, Semancik, and Duran-Vila, 1995), and grape plants (García-Arenal, Pallás, and Flores, 1987).

Due to the absence of viroid-encoded proteins, methods for viroid detection must rely on bioassays or nucleic acid-based approaches rather than protein-based serological ones. Diagnosis of citrus excortis disease was initially performed by an indicator plants, Etrog citron (Citrus medica L.) (Calavan, 1968). Molecular detection for CEVd was then achieved by several hybridization-related methods with/without gel electrophoresis (Fonseca, Marcellino, and Gander, 1996; Guo-Ping and Shikata, 1995; Murcia et al., 2009; Nakahara, Hataya, and Uyeda, 1999). Furthermore, with higher sensitivity and efficiency, reverse transcriptase-polymerase chain reaction (RT-PCR) (Bernad and Duran-Vila, 2006; Nakahara et al., 1999; Ragozzino, Faggioli, and Barba, 2004; Yang, Hadidi, and GARNSEY, 1992), multiplex RT-PCR (Ito, leki, and Ozaki, 2002; Wang et al., 2009) and real-time RT-PCR (Papayiannis, 2014; Saponari et al., 2012; Tessitori et al., 2004) were also developed for CEVd detection. However, due to the high sensitivity, PCR-based methods can show false positives resulted from contamination, while false negatives also can arise from the cDNA products of unsuitable size generated from reverse transcription (Murcia et al., 2009) or the failures of primer annealing caused by the nucleotide mutations within primer-binding sites of viroids (Lin, unpublished). Additionally, for inspection, quarantine and control of CEVd, a reliable, accurate, and rapid diagnostic procedure is needed. Therefore, it is desirable to employ more than one kind of diagnostic methods and/or at least two different pairs of primers to accurately identify or detect a specific viroid. Here, we developed an integrated diagnostic protocol for CEVd, comprised of defined bioindex of indicator plants, dot blot hybridization, one-step RT-PCR, and real-time RT-PCR. Moreover, a tomato model for studying CEVd pathogenesis was established as well. 


\section{Methods}

\subsection{Plant material, growth conditions and viroid sources}

Tomato cultivars Solanum lycopersicum L. cv. Rutgers select (from The World Vegetable Center, Tainan, Taiwan) and S. lycopersicum L. cv. Double-Fortune (Known-You Seed Co., Kaohsiung, Taiwan) plants were grown in pots with soil at $28^{\circ} \mathrm{C}$ in a 16 -h light / 8-h darkness cycle for four to six weeks.

The four viroid infectious clones, pBd-ASSVd (encodes for Apple skin scar viroid), pBd-CCCVd (encodes for Coconut cadang cadang viroid), pBd-CEVd (encodes for Citrus exocortis viroid) and pCM20d (encodes for Chrysanthemum chlorotic mottle viroid, CChMVd), were constructed by head-to-tail of viral genome and cloned into pBluescript SK (+) and kind gifts from Dr. Ricardo Flores, Instituto de Biología Molecular y Celular de Plantas, UPV-CSIC as described previously (Daros and Flores, 2004) pGA482-PSTVd contains monomeric Potato spindle tuber viroid (PSTVd) in a pGA482 binary vector as described previously (Itaya et al., 2001), which is a kind gift from Dr. Biao Ding (Ohio State University, Columbus, OH, USA).

\subsection{In vitro transcription and viroid inoculation}

pBd-CEVd was firstly linearized by $X$ hol digestion prior to being used as a template for in vitro transcription with T7 RNA polymerase in the MAXIscript kit (Ambion, TX, USA) according to manufacturer's instructions. Approximately $100 \mathrm{ng}$ of viroid transcripts were mechanically introduced onto cotyledon of 12 day-old tomato seedlings. The negative control of plants was mock-inoculated with 20 mM sodium phosphate buffer ( $\mathrm{pH}$ 7.0) as described previously (Cress, Kiefer, and Owens, 1983; Hu et al., 1997; Salazar et al., 1988; Zhu et al., 2002).

\subsection{Total RNA extraction}

$100 \mathrm{mg}$ of Rutgers or Double-Fortune leaves tissue were firstly ground with liquid nitrogen and $1 \mathrm{ml}$ of Trizol $^{\circledR}$ (Invitrogen, CA, USA) was added. The homogeneous lysate was transferred to a $1.5-\mathrm{ml}$ centrifuge tube and briefly vortexed. After incubation at $25^{\circ} \mathrm{C}$ for $5 \mathrm{~min}$, the samples were centrifuged at 13,200 rpm, $4^{\circ} \mathrm{C}$ for $10 \mathrm{~min}$. The supernatant was transferred to a new $1.5-\mathrm{ml}$ centrifuge tube and mixed with $0.2 \mathrm{ml}$ of chloroform. Each tube was vortexed for $15 \mathrm{sec}$ and incubated at $25^{\circ} \mathrm{C}$ for $3 \mathrm{~min}$. After centrifugation with $13,200 \mathrm{rpm}$ at $4^{\circ} \mathrm{C}$ for $10 \mathrm{~min}$, the supernatant was transferred to a new $1.5-\mathrm{ml}$ centrifuge tube and mixed well with $0.5 \mathrm{ml}$ of 2-propanol prior to further incubation at $25^{\circ} \mathrm{C}$ for $10 \mathrm{~min}$. Total RNAs were spun down with $13,200 \mathrm{rpm}$ at $4^{\circ} \mathrm{C}$ for $15 \mathrm{~min}$. Then, the supernatant was removed and RNA pellets were dissolved in DEPC-treated water and stored at $-80^{\circ} \mathrm{C}$.

\subsection{Preparation of examination of sensitivity limitation by in vitro transcripts}

To generate monomeric CEVd construct, we conducted the polymerase chain reaction (PCR) with PSTVdF-BamHI-88 / CEVd-R-BamHI-88 primer sets (see Table 1 for details) using the pBd-CEVd as templates. Then, the amplified PCR fragment of CEVd was cloned into pBluescript II SK (-) to obtain pBmCEVd. 
pBmCEVd was linearized by $X$ hol digestion and used for in vitro transcription with the mMESSAGE mMACHINE ${ }^{\circledR}$ in vitro transcription kit (Ambion, TX, USA) according to manufacturer's instructions. CEVd transcripts were then purified by the MEGAclear ${ }^{\circledR}$ Kit (Ambion) according to manufacturer's instructions. To measure the concentration of purified CEVd transcripts, a NanoDrop spectrophotometer (NanoDrop Technology, Rockland, DE) was employed. The molecular weight of CEVd transcripts was calculated by a tool of website, Oligonucleotide Properties Calculator (http://www.basic.northwestern.edu /biotools/oligocalc.html). Based on the quotient of concentration by the molecular weight of CEVd transcripts, the copy number was calculated.

\subsection{Dot blot hybridization}

For dot blot hybridization, the digoxigenin (DIG)-labeled full-length viroid CDNA probes of ASSVd, CCCVd, CEVd, and CM20d were prepared by PCR amplification using pBd-ASSVd, pBd-CCCVd, pBd-CEVd, pCM20d, and pGA482-PSTVd as templates, respectively. Total RNAs were spotted on nylon membranes (Schleicher \& Schuell Bioscience, NH) and then cross-linked by UV Stratalinker ${ }^{\circledR} 1800$ (Stratagene, CA). The membranes were pre-hybridized with DIG Easy Hyb Granules (DIG Northern Start Kit, Roche) at $65^{\circ} \mathrm{C}$ for $1 \mathrm{hr}$. DIG-labeled probes were denatured at $100^{\circ} \mathrm{C}$ for $5 \mathrm{~min}$ and were rapidly cooled on ice. Denatured probes were then immediately added and incubated at $65^{\circ} \mathrm{C}$ for overnight. Membranes were washed twice with $2 \times$ SSC, $0.1 \%$ SDS at RT for 5 min and additional twice with $0.1 \times$ SSC, $0.1 \%$ SDS buffer at $65^{\circ} \mathrm{C}$ for $15 \mathrm{~min}$. Afterward, membranes were rinsed with Maleate acid buffer $(0.1 \mathrm{M}$ Maleic acid, $0.15 \mathrm{M} \mathrm{NaCl}$, $\mathrm{pH} 7.5$ ) for 5 min. Blocking was carried out by incubation with Blocking solution (DIG Northern Start Kit, Roche) at RT for 30 min. Anti-DIG-AP Fab fragments were added into blocking solution (10000x dilution) and membranes were incubated at RT for 30 min. Membranes were washed twice with Maleate acid buffer at RT for $15 \mathrm{~min}$, and then washed once with detection buffer $(0.1 \mathrm{M} \mathrm{Tris-HCl}, 0.1 \mathrm{M} \mathrm{NaCl}, \mathrm{pH}$ to 9.5) at RT for $5 \mathrm{~min}$. Washed membranes were incubated with $1 \mathrm{ml}$ of CDP-star and exposed to X-film for 3 or $15 \mathrm{~min}$.

\subsection{One-step reverse transcription PCR}

One-step reverse transcription PCR (one step RT-PCR) was performed with One-step RT-PCR kit (Genemark, Taipei, Taiwan) according to manufacturer's instructions. $100 \mathrm{ng}$ of plant total RNAs were used to conduct one-step RT-PCR analyses in a $20 \mu$ reaction mixture with CEVd-F-96/CEVd-R-95 primer sets. After reverse-transcription at $55^{\circ} \mathrm{C}$ for $30 \mathrm{~min}$, the PCR condition was performed at $94^{\circ} \mathrm{C}$ for $5 \mathrm{~min}$, followed by $35 \mathrm{cycles}$ of $94^{\circ} \mathrm{C}$ for $30 \mathrm{sec}, 55^{\circ} \mathrm{C}$ for $30 \mathrm{sec}$, and $72^{\circ} \mathrm{C}$ for $25 \mathrm{sec}$. The reaction was completed and hold at $4^{\circ} \mathrm{C}$ after $10 \mathrm{~min}$ at $72^{\circ} \mathrm{C}$. These reactions were carried out in a Veriti ${ }^{\circledR} 96-$-Well Thermal Cycler (Applied Biosystems, CA, USA). The resulting PCR products were analyzed by electrophoresis on $1.5 \%$ agarose gel and detected by ethidium bromide staining.

\subsection{Real-time reverse transcription PCR}

To quantitate CEVd RNAs and tomato endogenous gene expressions, a real-time reverse transcription PCR (real-time RT-PCR) was employed. Briefly, first-strand cDNAs were synthesized from $1 \mu \mathrm{g}$ of total RNA 
using Moloney Murine Leukemia Virus Reverse Transcriptase (Invitrogen) according to the manufacturer's instructions. The CEVd-R-283 or oligo-dT 18 primer was used for detection of CEVd RNAs and expressions of host genes, respectively. Then, the PCR was conducted in a $10 \mu \mathrm{l}$ reaction mixture containing $50 \mathrm{ng}$ of cDNAs, $150 \mathrm{nM}$ forward primer (CEVd-F-100), $150 \mathrm{nM}$ reverse primer (CEVd-R-283) and $5 \mu \mathrm{l}$ of 2X SYBRgreen Mastermix ${ }^{\circledR}$ (Ampliqon, Odense, Denmark). The program for the PCR is performed for amplification at $50^{\circ} \mathrm{C}$ for $5 \mathrm{~min}$ and pre-denaturation at $95^{\circ} \mathrm{C}$ for $10 \mathrm{~min}$, followed by 40 cycles of $95^{\circ} \mathrm{C} \mathrm{for} 15 \mathrm{sec}$ and $60^{\circ} \mathrm{C}$ for $60 \mathrm{sec}$. The reaction was completed and hold at $40^{\circ} \mathrm{C}$ after analyses of melting curve. These reactions and analyses were carried out in a LightCycler 480 machine and software (Roche).

For each run, dedicated software of Real Time instrument plotted the fluorescence intensity against the number of cycles to give the threshold cycle (Ct) value using the automatic method. Standard curves were obtained by linear regression analysis plotting $\mathrm{Ct}$ values vesus the logarithm of the starting CEVd copy number, enabling estimation by interpolating the individual $\mathrm{Ct}$ values in the standard curve.

\section{Results}

\subsection{Quantification of CEVd-infected symptoms of tomato plants}

Initially, we sought for establishing a susceptible bio-indicator for CEVd infection and symptom development rather than using its typical exccortis symptom-expressing citrus hosts. Due to different sensitivity and tolerance to CEVd (Matoušek et al., 2007), various tomato cultivars were tested for suitability as CEVd bioindicators (data not shown). We produced dimeric RNA transcripts of CEVd via in vitro transcription for inoculation. Then, we maintained CEVd-inoculated tomato plants in growth chambers at high temperature and light intensity to enhance symptoms development of viroid-infected plants as described in Materials and Methods (Grasmick and Slack, 1985; Handley and Horst, 1988; Harris and Browning, 1980; Skoric et al., 2001). Among these, Rutgers (a sensitive tomato cultivar) and Double-Fortune (a local tomato cultivar in Taiwan) invariantly showed systematic symptoms (see below) and, thereafter, were chosen for further comparison on viroid symptomatic development and pathogenesis.

The early stage of CEVd-infected symptoms exhibited epinasity and leaf curl inward on the upper leaves of CEVd-infected Rutgers at 3 weeks post-infection (wpi) and showed further severity at 4 wpi (Fig. S1). At $6 \mathrm{wpi}$, in addition to the severe epinasty, leaf deformation and size reduction were observed on the upper leaves of CEVd-infected plants (Fig. 1A). Moreover, the lower leaves also showed epinasty and vein necrosis (Fig. 1B and S2), and the whole plant was prominently stunted (Fig. 1A left sides). On the contrary, CEVd-infected Double-Fortune did not often showed severe CEVd-infected symptoms in comparison with Rutgers (Fig. 1 right sides). Moreover, less reduction in the plant height induced by CEVd-infection is observed in Double-Fortune compared to that in Rutgers (Fig. 1A). These results indicate that Rutgers is more susceptible to CEVd-infection than Double-Fortune. 
To quantitate the severity of CEVd-infected tomato plants, the CEVd-infected symptoms displayed at 6 wpi were classified into five categories, such as stunting, leaf size reduction, epinasty, vein necrosis, and chlorosis (Fig. 2A) for bio-indexing. To this regard, the symptom severity of stunting and leaf size reduction were resulted from the reduction of height, length and width; on the other hand, the symptom severity of epinasty and vein necrosis were derived from the percentage of total leaflets showing symptoms. There were 11 levels ( 0 to 10$)$ for scoring the severity level of index symptoms, and only 2 levels ( 0 and 1$)$ for chlorosis.

Based on the results of indicator symptoms, the epinasty, leaf size reduction, vein necrosis and stunting of CEVd-inoculated Rutgers exhibited significant discrepancy compared with the mock plants, whereas Double-Fortune did not recapitulate the differences upon CEVd infection (Fig. 2B). Accordingly, it will be useful to enlist Rutgers as a bioindicator for CEVd diagnosis in the inspection and quarantine protocol.

\subsection{Rutgers as an indicator plant for CEVd infected citrus crops}

To test the applicability of Rutgers tomato as a CEVd bio-indicator for viroid-infected citrus plants in the farming field, same amounts of total RNAs extracted from the exocortis symptom-displaying or symptomless citrus plants (the citrus samples were collected from the citrus field in Douliu, Taiwan) (Fig. 3A) were inoculated to indicator Rutgers tomato plants. After $4 \mathrm{wpi}$, Rutgers started to display certain index symptoms (Fig. 3B). These results confirm that Rutgers can be employed as an indicator plant for diagnosing CEVd-infected citrus plants.

\subsection{An easy and nano-scaled diagnosis for CEVd by dot blot hybridization}

We generated and tested the DNA probes specific and sensitive for dot blot hybridization of CEVd to provide an easily molecular diagnosis. Firstly, we demonstrated that the probe displayed reasonably high specificity among different viroids (Fig. 4A). The sensitivity for the CEVd probe in dot blot hybridization was $0.41 \mathrm{ng}$. The result indicates that dot blot hybridization with this probe employed in this study provides a high specificity and sub-nanogram sensitivity for detection of the tested CEVd.

To mimic the actual RNA composition, a mixture of CEVd RNA transcripts and healthy tomato total RNAs at a ratio of 1:100 was used to establish a standard curve of the dot blot hybridization for CEVd RNA copy number. The result suggests that $10^{9}$ copies of CEVd RNAs is the detection limit for detecting CEVd in the dot blot hybridization (Fig. 4B).

To test the reliability which is more appropriate for diagnostic techniques of the dot blot hybridization for detecting CEVd in CEVd-infected plant samples, total RNAs from the CEVd-infected tomato and the CEVdinfected Gynura aurantiaca were isolated and then subjected to the dot blot hybridization. We obtained specific CEVd signals with limitations at 31 and $12 \mathrm{ng}$ of total RNAs from the CEVd-infected tomato and the CEVd-infected Gynura aurantiaca, respectively. (Fig. 4C). In light of the standard curve performed above (Fig. 4B), the converted CEVd copy numbers for both infected plant samples are $4.8 \times 10^{7}$ and 9.2 $\times 10^{7}$ per ng of citrus and Gynura aurantiaca RNA, respectively. 
Total RNAs isolated from healthy or suspected CEVd-infected citrus samples displaying exocortis symptom collected in the farming field were also subjected to dot blot hybridization (Fig. 4D). We determined that the CEVd copy number in the tested citrus was around $1.4 \times 10^{7}$ in per $1 \mathrm{ng}$ of citrus total RNAs.

\subsection{One-step RT-PCR provides a fast, sensitive and accurate way for CEVd detection}

To date, PCR-based diagnostic approaches are commonly used to provide fast, sensitive, and accurate diagnostic methods for detecting viral pathogens. We hereof developed one-step RT-PCR and real-time RTPCR for CEVd detection. Using in vitro transcribed CEVd dimers as templates, the RNA titration of onestep RT-PCR shows that the sensitivity of CEVd RNA transcripts was less than $10^{8}$ copies (Fig. 5A). To test the applicability of the one-step RT-PCR in the detection of CEVd-infected plants, the total RNAs extracted from CEVd-infected or mock tomato plants were subjected to the one-step RT-PCR analysis as described in Materials and Methods. We demonstrated that CEVd could be detected from CEVd-infected tomato plants by the one-step RT-PCR whereas the mock control showed negative signal (Fig. 5B). The detection limitations for both CEVd-infected tomato and Gynura aurantiaca plants were as low as $10 \mathrm{ng}$ of total RNA (Fig. 5C) and the copy number per ng of the total RNAs is calculated as $4.8 \times 10^{7}$ and $2.0 \times$ $10^{7}$ copies, respectively. Citrus samples displaying typical exocortis symptoms also showed positive results in the one-step RT-PCR with a calculated concentration of $4.5 \times 10^{7}$ copies per ng of total RNA (Fig. 5C). Further sequence analysis showed that the AD3 CEVd strain found in Taiwan shares $98 \%$ identity to the CEVd strain used in this study (M34917-G74A; (Daros and Flores, 2004)), differing in 6 nucleotides (Fig. 6).

\subsection{Quantitative detection of CEVd by real-time RT-PCR}

Next, we established a standard curve based on the amplification curves and the melting peaks of the real-time RT-PCR for CEVd transcripts as described in the Materials and Methods, which enables directly and absolutely measuring the quantity of CEVd (Fig. 7A). In the standard curve, a linear correlation was observed for six logarithmic concentrations with an $R$ square value of 0.995 , indicating an intimate reliability for calculating CEVd's quantities within the range of the examined concentrations. Purified total RNAs from tomato and citrus were subjected to the test. The results of the RNA titration real-time RT-PCR suggest that the detection limits are $5.9 \times 10^{6}$ and $3 \times 10^{6}$ copies in per $1 \mathrm{ng}$ of total RNA for tomato and citrus plants, respectively (Fig. 7B). Together, these data indicate that real-time RT-PCR confers more sensitivity than other methods, such as one-step RT-PCR and dot blot hybridization, for detecting CEVd.

\subsection{The correlation between the level of CEVd RNAs/sRNAs and CEVd-infected symptoms}

The discrepancy on the symptom expression of CEVd-infected tomato plants was noticed between Rutgers and Double-Fortune as documented in Fig 1. To explore the potential culprit leading to the discrepancy, we first examined the viroid genomic RNA level in the both CEVd-infected tomato plants. However, there is no significant difference on the accumulative viroid genomic RNA level and the 
expression of CEVd-derived-small RNAs (sRNAs) between CEVd-infected Rutgers and Double-Fortune by Northern hybridization and real-time PCR (data not shown). These results indicated that CEVd enables successfully replicated in both tomato cultivars despite Double-Fortune might be more tolerant than Rutgers in response to CEVd infection. In addition, symptoms on CEVd-infected Rutgers are prominent but diverse at 6 wpi (Fig. 8A). The leaves exhibiting various degrees of symptoms (mild and severe, also being indicated by the index described above) at the same position of CEVd-infected Rutgers were collected and were subjected to comparison of the levels of CEVd genomic RNAs and sRNAs. As a result, the leaves with severe symptoms appeared to have accumulated higher levels of CEVd genomic RNAs and sRNAs than the leaves with mild symptoms (Fig. 8B). In addition, the level of CEVd sRNAs is also associated with level of the viroid genomic RNA (Fig. 8C). Interestingly, a positive correlation between CEVd sRNAs and symptom severity was found. Taken together, our results implicate that the severity of CEVd-induced symptoms may be associated with higher amount of replicative CEVd genome and/or accumulative viroid-derived small RNAs.

\section{Table 1. Primer and probe sequences used in this study}

\begin{tabular}{llll} 
Names & Sequence $\left(\right.$ ('-3') $\left.^{\prime}\right)$ & Accession number & Reference \\
\hline PSTVd-F-BamHI-88 & GCGGATCCCCGGGGAAACCTGG & V01465 & This study \\
\hline PSTVd-R-BamHI-87 & GCGGATCCTGAAGCGCTCCTCCGAG & V01465 & This study \\
\hline CEVd-R-BamHI-88 & GCGGATCCTGAAGGACTTCTTCCCC & M34917; G74 $\rightarrow \Delta$ & This study \\
\hline CEVd-F-96 & CGGGGAAACCTGGAGGAA & M34917; G74 $\rightarrow \Delta$ & This study \\
\hline CEVd-R-95 & GGGATCCCTGAAGGACTTCTT & M34917; G74 $\rightarrow \Delta$ & This study \\
\hline CEVd-F-100 & GAAACCTGGAGGAAGTCGAG & M34917; G74 $\rightarrow \Delta$ & This study \\
\hline CEVd-R-283 & AGTTGTTTCCACCGGGTAGTATC & M34917; G74 $\rightarrow \Delta$ & This study \\
\hline Oligo-dT 18 & TTTTTTTTTTTTTTTTTT & & This study
\end{tabular}

The restriction endonuclease sites are underlined.

\section{Discussion}

\subsection{Bio-index and molecular methods for detection}

The initial attempt of this study is to seek an indicator plant for CEVd inspection and quarantine uses. Although CEVd readily infects tomato plants, distinguishable symptoms among various tomatoes cultivars, for example, on both Rutgers- and Double-Fortune tomato plants, exhibit statistical discrepancy on the severity and progression of the disease (Fig. 1 and 2). Our finding not only established a bioindicator for CEVd symptom expression, but also provided a basis for understanding the molecular mechanism underlying CEVd pathogenesis. Hence, in need of a reliable standard of protocol for CEVd 
detection/diagnosis, we first established an integrated diagnostic approach, including bio-index in a tomato cultivar Rutgers, dot blot hybridization with CEVd molecular probes, one-step RNA and real-time RT-PCR, as a reliable, accurate, and rapid method used for CEVd detection.

\subsection{Tomato plant as a bioindicator for CEVd}

Among susceptible hosts, the suitability of tomato plant on serving as an indicator plant for CEVd is attributed by several advantages as shorter growth time, small size, rapidness for symptom expression (4-6 weeks), and a model organism for plant science. Firstly, it takes shorter time, i.e. 4-6 weeks, to display CEVd-related symptoms on tomato plants than on citrus plants for more than 6 months. Secondly, it is easier to obtain more information from tomato due to its property as a model plant; lastly, there are also more genetic or molecular tools for studies of tomato plant so that studies of the interactions between viroid and tomato in the future can be more easily achieved.

After inoculation of CEVd transcripts, cv. Rutgers showed typical symptoms of PSTVd or CEVd, which were consistent with previous studies (Harris and Browning, 1980; Owens and Hammond, 2009; Qi and Ding, 2003; Sano et al., 1992). Although various variants of CEVd might be limited to specific hosts, in our case, CEVd isolated from citrus in field could infect tomato cv. Rutgers systemically and then caused epinasty, vein necrosis, and stunting at 4 to 6 wpi. Hence, CEVd-sensitive cv. Rutgers may be a great indicator plant host for CEVd diagnosis, amplification of CEVd quantities, and further studies of viroids, such as distinguishing viroid variants of different severity and/or investigate the pathogenic nucleotides and domains of viroids (Morris and Wright, 1975; Owens et al., 1996; Qi and Ding, 2003; Sano et al., 1992). On the other hand, the fact that Double-Fortune is not a good indicator plant for viroids potentially makes it a better candidate for studying essential factors involved in tolerance to viroids. Also, the tolerant cultivar could be bred with other high-value or sensitive cultivars to obtain new cultivars that might be more commercially profitable with tolerance to viroid infection.

\subsection{CEVd isolated from citrus in the farming citrus field}

The sequences were not fully identical between CEVd used in this study (M34917-G74 $\Delta$ ) and CEVd from AD3 citrus in field (Fig. 6); however, the nucleotide change of primer-binding sites might not be obtained unless another set of primers is used. Because the symptoms of tomato plants infected by M34917G74 $\Delta$ and AD3 were mostly the same, it might indicate that the nucleotide changes did not affect the pathogenicity of these two CEVd variants on tomato host. In addition, CEVd from two tomato plants infected by AD3 citrus total RNA were identical to the initial inoculum, AD3, at least in the sequenced region. In addition, based on nearly $98 \%$ sequence identities between $A D 3$ and the Chinese variant DQ431991, Citrus exocortis viroid isolate CEVd-XNM-ZK Guangdong-YC (data not shown), the AD3 variant might be imported from China or vice versa.

\subsection{Implications for CEVd pathogenesis}


We found a positive association in the accumulation of CEVd gRNAs with the symptomatic severity of CEVd-infected Rutgers tomato plants (Fig. 8). In contrast, it insignificantly recapitulated these differences between the two tomato cultivars, Rutgers and Double-Fortune (data not shown) although they exhibited distinguishable symptomatic expressions (Fig. 1 \& 2), which could result from the genetic variation of two tomato cultivars. One study has indicated that varied genotypic tomato plants render different susceptibility to viroid infection, which is dispensable at the levels of viroid replication in sensitive and tolerant plants (Matoušek et al., 2007). It is thus desirable to further identify other host factors which may lead to the noticeable differences in symptom expression on these two cultivars.

\section{Conclusions}

For the diagnostic purpose, we statistically assessed the CEVd-infected symptoms in tomato cultivars Rutgers and Double-Fortune in search of a suitable bio-indicator for CEVd disease. Base on the selected five bio-indexes comprised epinasty, vein necrosis, stunting, and reduction of leaf length and width, tomato cv. Rutgers was demonstrated to serve as a better indicator plant for CEVd in comparison with Double-Fortune. In addition, combination with molecular detections of CEVd RNAs, including dot blot, one-step RT-PCR and real-time RT-PCR, we were able to monitor the existence, distribution, amount as well as even pathogenicity and pathogenesis of CEVd. Among these, the sensitivities of three molecular methods were compared and showed that real-time RT-PCR conferred the best sensitivity of $10^{7}$ copies of CEVd. On the other hand, indicator plants and bio-index could help recognition of different severity of viroids and were good models for further studies in the mechanism of viroid pathogenesis. To sum up, for further researches of viroid pathogenesis and viroid-host interactions, indicator plants and real-time RT-

PCR were more appropriate; for larger scale of detection work of quarantine, dot blot and one-step RT-PCR seem to be more suitable, due to the lower cost of time and money.

\section{Abbreviations}

ASSVd: Apple skin scar viroid

CBCVd: Citrus bark cracking viroid

CBLVd: Citrus bent leaf viroid

CCCVd: Coconut cadang cadang viroid

CChMVd: Chrysanthemum chlorotic mottle viroid

CDVd: Citrus dwarfing viroid

CEVd: Citrus exocortis viroid

CVd-V: Citrus viroid V 
CVd-Vl: Citrus viroid VI

HSVd: Hop stunt viroid

PSTVd: Potato spindle tuber viroid

RT-PCR: reverse transcriptase-polymerase chain reaction

WPI: week post-inoculation

\section{Declarations}

\section{Ethics approval and consent to participate}

Not applicable

Consent for publication

Not applicable

Availability of data and materials

Not applicable

Competing interests

The authors declare that they have no competing interests.

\section{Funding}

Not applicable

\section{Authors' contributions}

$\mathrm{CH}$ Lin, I Hu and CY Lin carried out the experimental work under the supervision of TH Hung and TL Shen. TH Hung, ML Wu, TL Shen participated in the experiment design and analyzed data. CH Lin and TL Shen wrote the manuscript. All authors have read and approved the final manuscript.

\section{Acknowledgements}

This study is supported by Ministry of Science and Technology (100-2321-B-002-033-MY3) and Council of Agriculture, Taiwan (to TL Shen). We thank Dr. Biao Ding for critical reading this manuscript and helpful comments.

\section{References}


Adams MJ, Lefkowitz EJ, King AMQ, Harrach B, Harrison RL, Knowles NJ, et al. Ratification vote on taxonomic proposals to the International Committee on Taxonomy of Viruses. Arch. Virol. 2016; 161(10), 2921-2924.

Bernad L, Duran-Vila N. A novel RT-PCR approach for detection and characterization of citrus viroids. Mol. Cell Probes. 2006; 20(2), 105-113.

Calavan E. Exocortis. Indexing procedures for 15 citrus diseases of citrus trees.

Agricultural handbook no. 33. ARS: USDA, 1968. p. 23-34.

Cress DE, Kiefer MC, Owens RA. Construction of infectious Potato spindle tuber viroid cDNA clones. Nucleic Acids Res. 1983; 11(19), 6821-6835.

Daròs, JA, Elena, SF, Flores R. Viroids: an Ariadne's thread into the RNA labyrinth. EMBO Rep. 2006; 7(6), 593-598.

Daros, JA, Flores R. Arabidopsis thaliana has the enzymatic machinery for replicating representative viroid species of the family Pospiviroidae. Proc. Natl. Acad. Sci. U. S. A. 2004; 101(17), 6792-6797.

Ding B. The biology of viroid-host interactions. Annu Rev Phytopathol. 2009; 47, 105-131

Ding B, Itaya A. Viroid: a useful model for studying the basic principles of infection and RNA biology. Mol.Plant-Microbe Interact. 2007; 20(1), 7-20.

Ding B, Wang Y. Viroids: uniquely simple and tractable models to elucidate regulation of cell-to-cell trafficking of RNA. DNA Cell Biol. 2009; 28(2), 51-56.

Fadda Z., Daròs J, Flores R, Duran-Vila N. Identification in eggplant of a variant of citrus exocortis viroid (CEVd) with a 96 nucleotide duplication in the right terminal region of the rod-like secondary structure. Virus Res. 2009; 97(2), 145-149.

Fagoaga C, DuranVila N. Naturally occurring variants of citrus exocortis viroid in vegetable crops. Plant Pathol. J. 1996; 45(1), 45-53.

Fagoaga C, Pina J, Duran-Vila N. Occurrence of small RNAs in severely diseased vegetable crops. Plant Disease. 1994; 78(7), 749-753.

Fagoaga C, Semancik JS, Duran-Vila N. A citrus exocortis viroid variant from broad bean (Vicia faba L.): infectivity and pathogenesis. J. Gen. Virol. 1995; 76, 2271-2277.

Flores R, Hernandez C, Martinez de Alba A, Daros J, Di Serio F. Viroids and viroid-host interactions. Annu Rev Phytopathol. 2005; 43, 117-139. 
Fonseca ME, Marcellino LH, Gander E. A rapid and sensitive dot-blot hybridization assay for the detection of Citrus exocortis viroid in Citrus medica with digoxigenin-labelled RNA probes. J. Virol. Methods. 1996; 57(2), 203-207.

García-Arenal F, Pallás V, Flores R. The sequence of a viroid from grapevine closely related to severe isolates of Citrus exocortis viroid. Nucleic Acids Res. 1987; 15,(10) 4203-4210.

Grasmick ME, Slack SA. Symptom expression enhanced and low concentrations of Potato spindle tuber viroid amplified in tomato with high light intensity and temperature. Plant Dis. 1985; 69, 49-51.

Guo-Ping W, Shikata E. Gene diagnosis of viroids: comparisons of return-PAGE and hybridization using DIG-labeled DNA and RNA probes for practical diagnosis of Hop stunt, Citrus exocortis and Apple scar skin viroids in their natural host plants. Ann. Phytopathol. Soc. Japan. 1995; 61(4), 381-390.

Handley M, Horst R. The effect of temperature and light on Chrysanthemum stunt viroid infection of florists chrysanthemum. VII International Symposium on Virus Diseases of Ornamental Plants. 1988; 234(10), 89-98.

Harris P, Browning I. The effects of temperature and light on the symptom expression and viroid concentration in tomato of a severe strain of Potato spindle tuber viroid. Am. J. Potato Res. 1980; 23, 8593.

Hu Y, Feldstein PA, Hammond J, Hammond RW, Bottino PJ, Owens RA. Destabilization of Potato spindle tuber viroid by mutations in the left terminal loop. J. Gen. Virol. 1997; 78, 1199-1206.

Itaya A, Folimonov A, Matsuda Y, Nelson RS, Ding B. Potato spindle tuber viroid as inducer of RNA silencing in infected tomato. Mol. Plant Microbe interact. 2001; 14(11), 1332-1334.

Ito T, leki H, Ozaki K. Simultaneous detection of six citrus viroids and Apple stem grooving virus from citrus plants by multiplex reverse transcription polymerase chain reaction. J. Virol. Methods. 2002; 106(2), 235-239.

Ito T, leki H, Ozaki K, Ito T. Characterization of a new citrus viroid species tentatively termed Citrus viroid OS. Arch. Virol. 2001; 146(5), 975-982.

Keese P, Symons R. Domains in viroids: evidence of intermolecular RNA rearrangements and their contribution to viroid evolution. Proc. Natl. Acad. Sci. 1985; U. S. A. 82(14), 4582-4586.

Løvdal T, Lillo C. Reference gene selection for quantitative real-time PCR normalization in tomato subjected to nitrogen, cold, and light stress. Anal. Biochem. 2009; 387(2), 238-242.

Matoušek J, Kozlová P, Orctová L, Schmitz A, Pešina K, Bannach O, et al. 2007. Accumulation of viroidspecific small RNAs and increase in nucleolytic activities linked to viroid-caused pathogenesis. J. Biol. Chem. 2007; 388(1), 1-13. 
Mishra MD, Hammond RW, Owens RA, Smith DR, Diener TO. Indian bunchy top disease of tomato plants is caused by a distinct strain of Citrus exocortis viroid. J Gen. Virol. 1991; 72, 1781-1785.

Morris T, Wright N. Detection on polyacrylamide gel of a diagnostic nucleic acid from tissue infected with Potato spindle tuber viroid. Am. J. Potato Res. 1975; 52, 57-63.

Murcia N, Serra P, Olmos A,Duran-Vila N. A novel hybridization approach for detection of citrus viroids. Mol. Cell. Probes. 2009; 23(2), 95-102.

Nakahara K, Hataya T, Uyeda I. A simple, rapid method of nucleic acid extraction without tissue homogenization for detecting viroids by hybridization and RT-PCR. J. Virol. Methods. 1999; 77(1), 47-58.

Owens R, Hammond R. Viroid pathogenicity: one process, many faces. Viruses. 2009; 1(2), 298-316.

Owens RA, Steger G, Hu Y, Fels A, Hammond RW, Riesner D. RNA structural features responsible for Potato spindle tuber viroid pathogenicity. Virology. 1996; 222(1), 144-158.

Papayiannis LC. Diagnostic real-time RT-PCR for the simulataneous detection of Citrus exocortis viroid and Hop stunt viroid. J. Virol. Methods. 2014; 196, 93-99.

Qi Y, Ding B. Inhibition of cell growth and shoot development by a specific nucleotide sequence in a noncoding viroid RNA. Plant Cell. 2003; 15(6), 1360-1374.

Ragozzino E, Faggioli F, Barba M. Development of a one tube-one step RT-PCR protocol for the detection of seven viroids in four genera: Apscaviroid, Hostuviroid, Pelamoviroid and Pospiviroid. J. Virol. Methods. 2004; 121(1), 25-9.

Salazar L, Hammond R, Diener T, Owens R. Analysis of viroid replication following Agrobacteriummediated inoculation of non-host species with Potato spindle tuber viroid cDNA. J. Gen. Virol. 1988; 69(4), 879-889.

Sano T, Candresse T, Hammond RW, Diener TO, Owens RA. Identification of multiple structural domains regulating viroid pathogenicity. Proc. Natl. Acad. Sci. U. S. A. 1992; 89(21), 10104-10108.

Saponari M, Loconsole G, Saldarelli P, Doddapaneni H, Savino V, Martelli G. Identification of a singlestanded DNA virus associated with citrus chlorotic dward disease, a new member in the family Geminivirdae. Virology. 2012; 432, 162-172.

Semancik JS, Weathers LG. Exocortis disease: evidence for a new species of "infectious" low molecular weight RNA in plants. Nature New Biol. 1972; 237, 242-244.

Skoric D, Conerly M, Szychowski JA, Semancik JS. CEVd-induced symptom modification as a response to a host-specific temperature-sensitive reaction. Virology. 2001; 280, 115-123. 
Tessitori M, Rizza S, Reina A, Catara A. Real-Time RT-PCR based on SYBR-Green I for the detection of citrus exocortis and citrus cachexia diseases. Proceedings of the 16th Conference of the International Organization of Citrus Virologists. 2004; 456-459.

Tsagris E, de Alba A, Gozmanova M, Kalantidis K. Viroids. Cell. Microbiol. 2008; 10(11), 2168-2179

Uppalapati SR, Ayoubi P, Weng H, Palmer DA, Mitchell RE, Jones W, Bender CL. The phytotoxin coronatine and methyl jasmonate impact multiple phytohormone pathways in tomato. Plant J. 2005; 42(2), 201-217.

Uppalapati SR, Ishiga Y, Wangdi T, Kunkel BN, Anand A, Mysore KS, et al. The phytotoxin coronatine contributes to pathogen fitness and is required for suppression of salicylic acid accumulation in tomato inoculated with Pseudomonas syringae pv. tomato DC3000. Mol. Plant-Microbe Interact. 2007; 20(8), 955-965.

Van Den Burg HA, Tsitsigiannis DI, Rowland O, Lo J, Rallapalli G, Maclean D, Takken FLW, Jones JDG. The F-Box Protein ACRE189/ACIF1 Regulates Cell Death and Defense Responses Activated during Pathogen Recognition in Tobacco and Tomato. Plant Cell 20(3). 2008; 697-719.

Verhoeven J, Jansen C, Willemen T, Kox L, Owens R, Roenhorst J. Natural infections of tomato by Citrus exocortis viroid, Columnea latent viroid, Potato spindle tuber viroid and Tomato chlorotic dwarf viroid. Eur. J. Plant Pathol. 2004; 110, 823-831.

Vernière C, Perrier X, Dubois C, Dubois A, Botella L, Chabrier C, Bové JM, Vila ND. Interactions Between Citrus Viroids Affect Symptom Expression and Field Performance of Clementine Trees Grafted on Trifoliate Orange. Phytopathology. 2006; 96(4), 356-368.

Walter AE, Turner DH, Kim, J, Lyttle M.H, Müller P, Mathews DH, Zuker M. Coaxial stacking of helixes enhances binding of oligoribonucleotides and improves predictions of RNA folding. Proc. Natl. Acad. Sci. U. S. A. 1994; 91(20), 9218-9222.

Wang X, Zhou C, Tang K, Zhou Y, Li Z. A rapid one-step multiplex RT-PCR assay for the simultaneous detection of five citrus viroids in China. Eur. J. Plant Pathol. 2009; 124, 175-180.

Yang X, Hadidi A, Garnsey S. Enzymatic cDNA amplification of citrus exocortis and cachexia viroids from infected citrus hosts. Phytopathology. 1992; 82(3), 279-285.

Zhu Y, Qi Y, Xun Y, Owens R, Ding B. Movement of Potato spindle tuber viroid reveals regulatory points of phloem-mediated RNA traffic. Plant Physiol. 2002; 130, 138-146.

Zuker, M. Mfold web server for nucleic acid folding and hybridization prediction. Nucleic Acids Res. 2003; 31(13), 3406-3415.

\section{Figures}



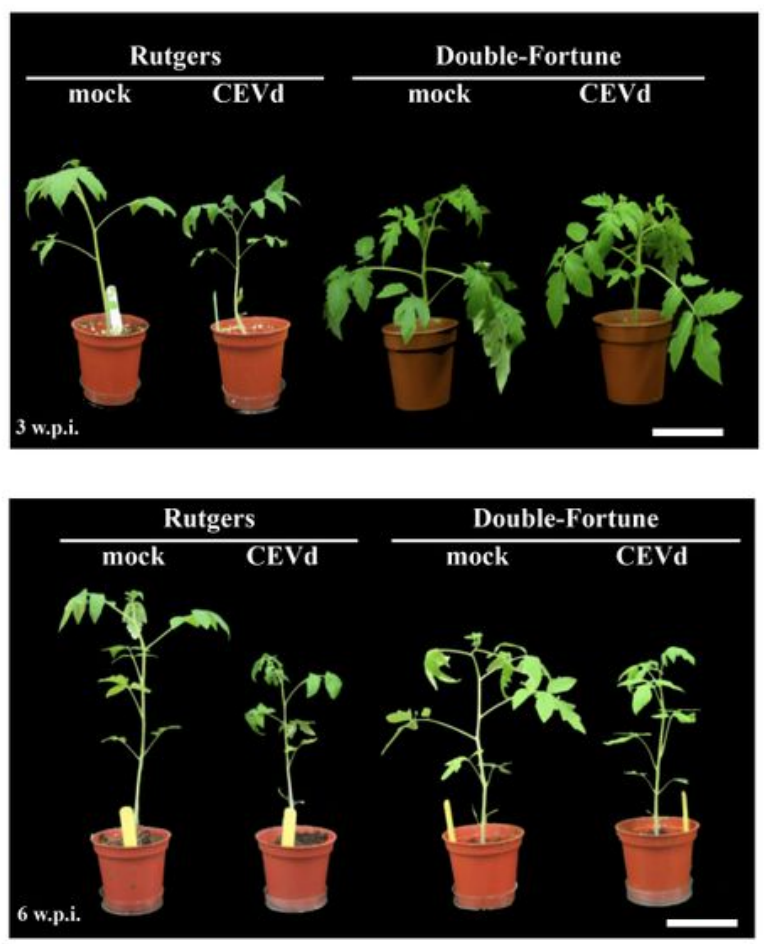

Figure 1B
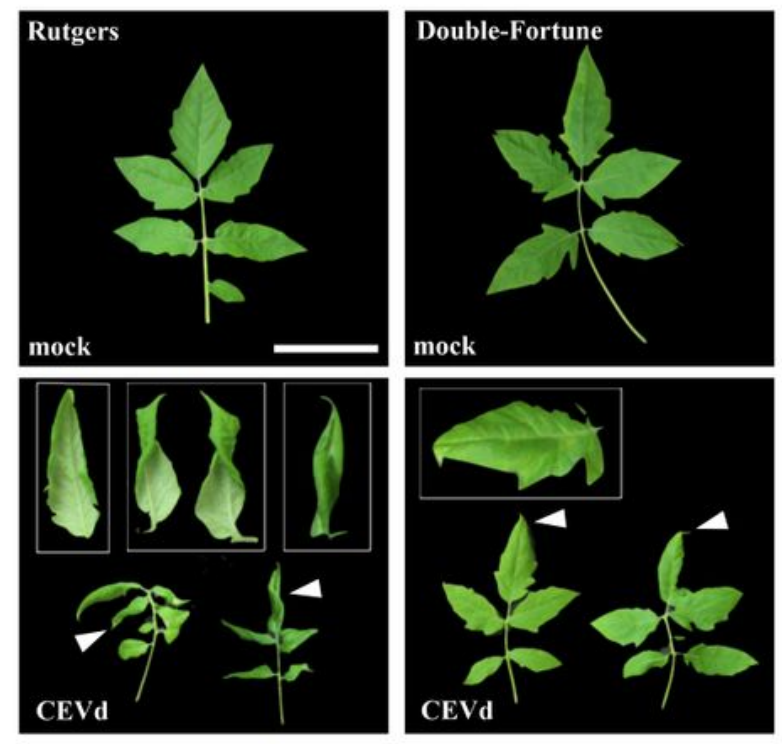

\section{Figure 1}

Symptoms of susceptible tomato plants infected by Citrus exocortis viroid (CEVd). (A) The symptoms of CEVd-inoculated tomato plants (S. lycopersicum cv. Rutgers and Double-Fortune) at 3 or 6 week postinoculation (w.p.i). The scale bar $=10 \mathrm{~cm}$. (B) The upper leaves of CEVd-infected symptoms on tomato plants. The scale bar $=5 \mathrm{~cm}$. 


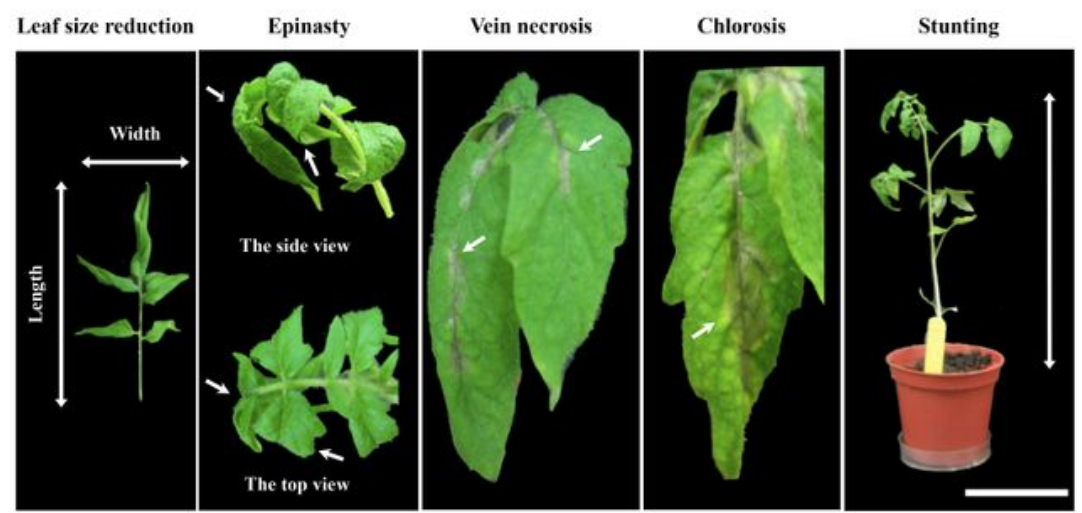

Figure 2B
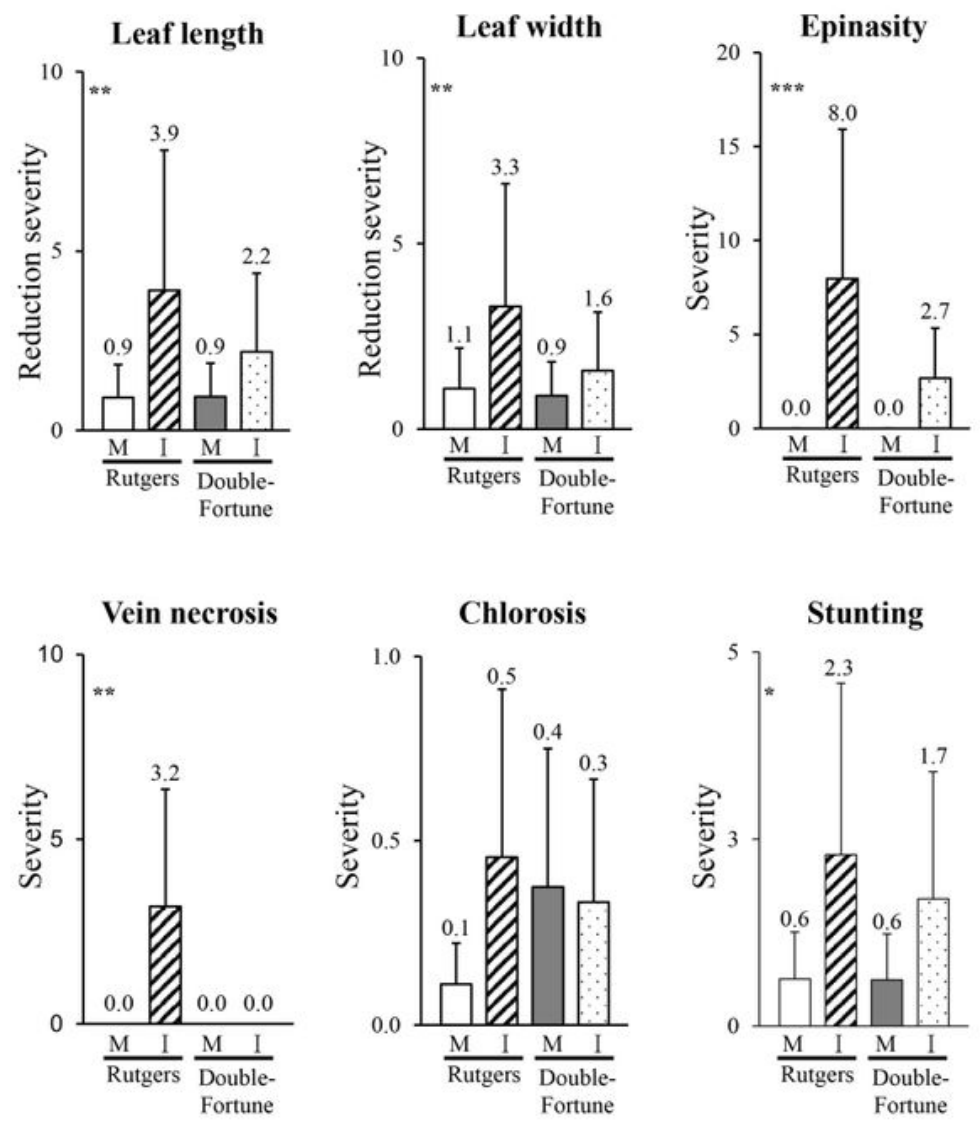

\section{Figure 2}

Symptoms on CEVd-infected Rutgers tomato plants as a bio-index. (A) Categories of CEVd-infected symptoms showed on Rutgers tomato plants and could be used as a bio-index for CEVd infection. (B) Quantification of CEVd-infection symptoms on Rutgers and Double-Fortune at 6 wpi. Error bars indicated \pm standard deviation of the mean of at least three times experiments. Statistically significant differences 
for values were determined by Student's $t$ test ( $P<0.05$, $* \star P<0.01$, $* \star \star P<0.001)$. M: mock-inoculated tomato plants; I: CEVd-inoculated tomato plants. The scale bar $=5 \mathrm{~cm}$.

Figure 3

A.
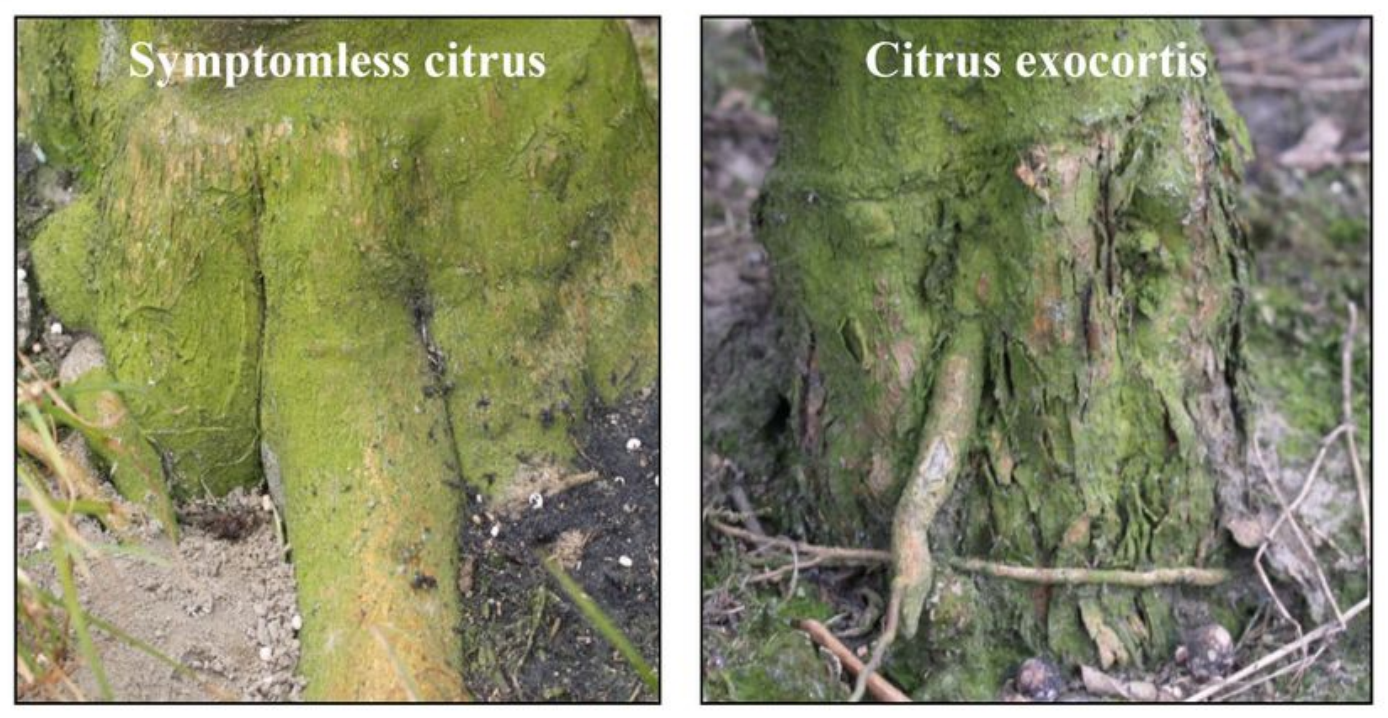

B.
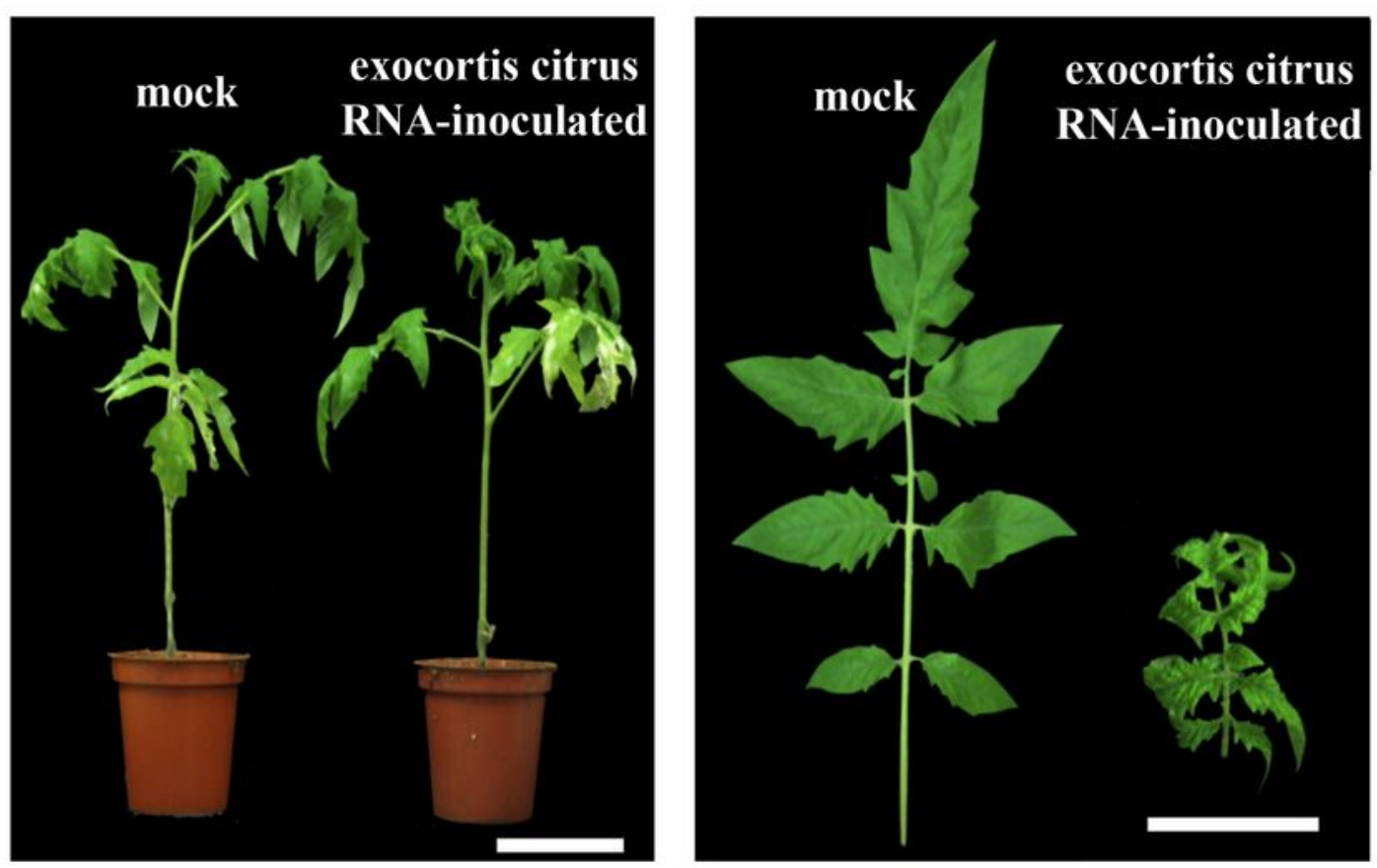

\section{Figure 3}

Symptoms of citrus and Rutgers tomato plants caused by CEVd in the field. (A) Exocortis and symptomless citrus from the field. (B) Field-collected citrus samples were inoculated on Rutgers index 
plants. Right panel displays a close-up view of the upper leaves. The photographs were taken at 4 wpi. Scale bar left: $10 \mathrm{~cm}$; left: $5 \mathrm{~cm}$.

\section{Figure 4}

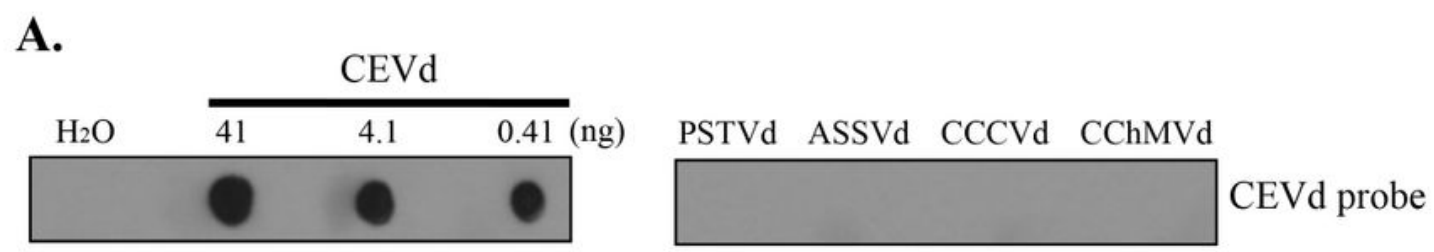

B. Healthy tomato RNA

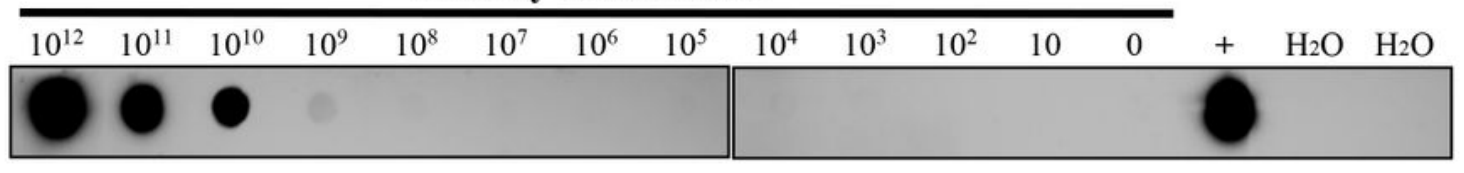

C. CEVd-inoculated tomato plant CEVd-infected Gynura aurantica plant

\begin{tabular}{|cccccccc|}
\hline 1000 & 500 & 250 & 125 & 63 & 31 & 16 & 8 \\
\hline & 0 & 0 & 0 & 0 & 0 & & \\
\hline
\end{tabular}

\begin{tabular}{|ccccccccc}
\hline 200 & 100 & 50 & 25 & 12 & 6 & 3 & 1 & (ng) \\
0 & 0 & 0 & 0 & & & & & \\
\hline
\end{tabular}

D. Citrus samples from the field

\begin{tabular}{|c|c|c|c|c|c|c|}
\hline $\mathrm{AHl}$ & $\mathrm{AH} 2$ & $\mathrm{AH} 2$ & AD3 & AD4 & DG & $\mathrm{H}_{2} \mathrm{O}$ \\
\hline
\end{tabular}

\section{Figure 4}

Dot blot hybridization of CEVd. (A) Probe specificity test for CEVd dot blot hybridization detection. (B) Dot blot hybridization sensitivity test for CEVd detection. (C) Detection of CEVd-infected tomato and Gynura aurantiaca RNAs by dot blot hybridization. (D) Detection of CEVd-infected citrus from the farming field by 
dot blot hybridization. +: CEVd plasmid; DT: CEVd-infected tomato plant; DG: CEVd-infected Gynura aurantiaca; AH1-AD4: field samples showing no symptoms (AH) or suspected symptoms (AD).

\section{Figure 5}

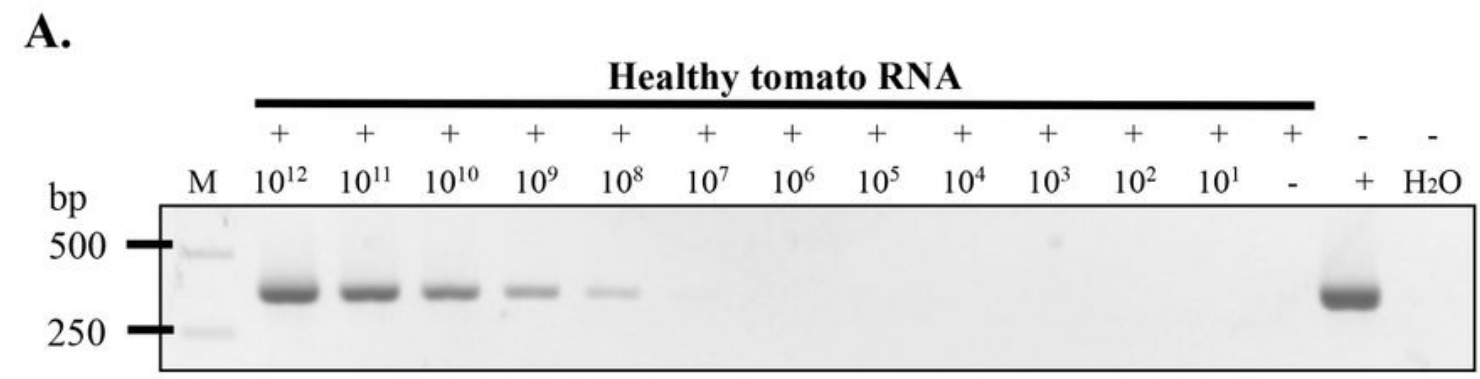

B.

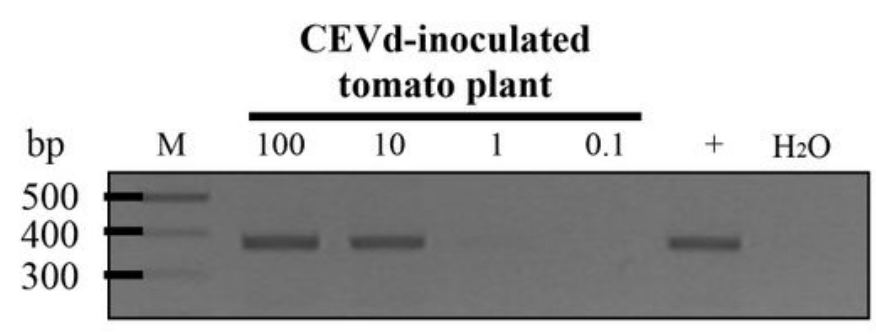

\section{CEVd-infected Gynura} aurantiaca plant

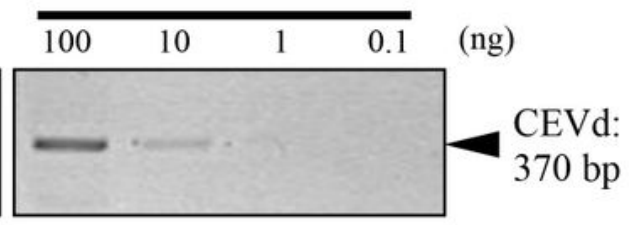

C.

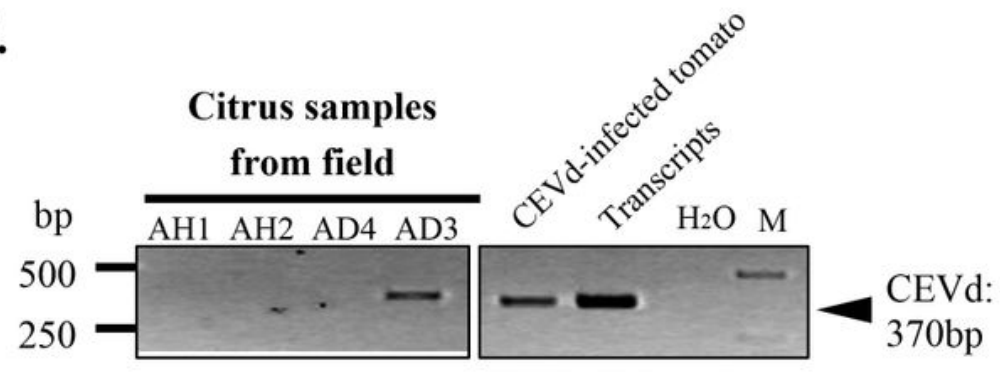

Figure 5

CEVd detection by one-step RT-PCR. (A) One-step RT-PCR sensitivity test for CEVd detection. (B) Detection of CEVd-infected tomato plants by one-step RT-PCR. Elongation factor 1 alpha (EF-1a) was used as an internal control. (C) Detection of CEVd-infected citrus from the farming field by one-step RT-PCR. +: CEVd 
plasmid; DT: CEVd-infected tomato plant; DG: CEVd-infected Gynura aurantiaca; AH1-AD4: field samples showing no symptoms (AH) or suspected symptoms (AD).

Figure 6

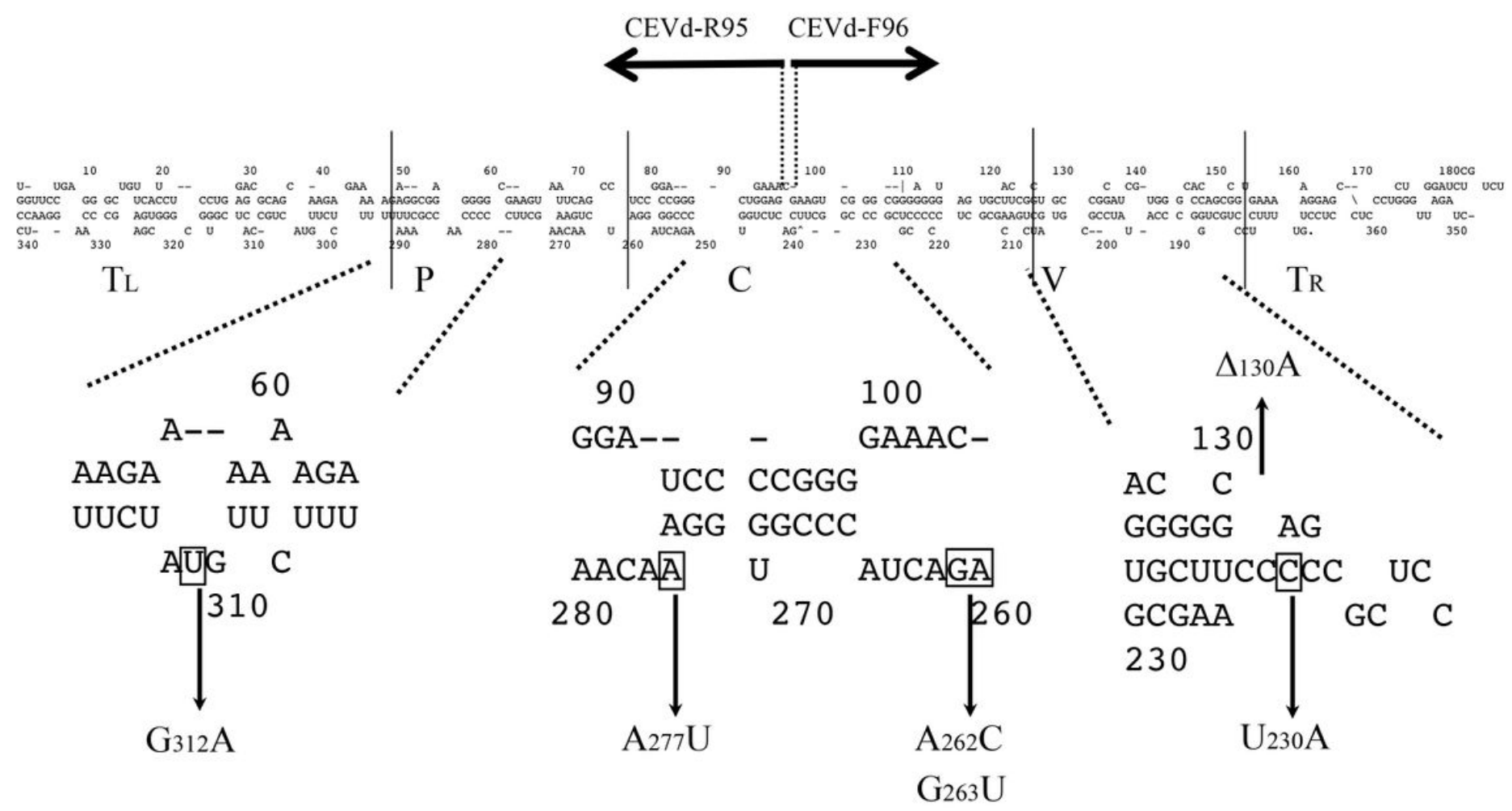

Figure 6

Sequence comparison between CEVd M34917-G74 $\Delta$ strain and a CEVd isolate from the field. Secondary structures of the minimum free energy at $24^{\circ} \mathrm{C}$ of CEVd strain (M34917-G74 $\Delta$ ) were predicted by the Mfold program (Walter et al., 1994; Zuker, 2003). CEVd-F96 and CEVd-R95 primers were used in one-step RT-PCR and sequencing. The nucleotide variations between M34917-G74 $\Delta$ and a CEVd isolate from citrus farming field were indicated. TL (Terminal left), P (Pathogenicity), C (Central), V (Variable) and TR (Terminal right) refer to the structural domains of the viroid secondary structure (Keese and Symons, 1985). 

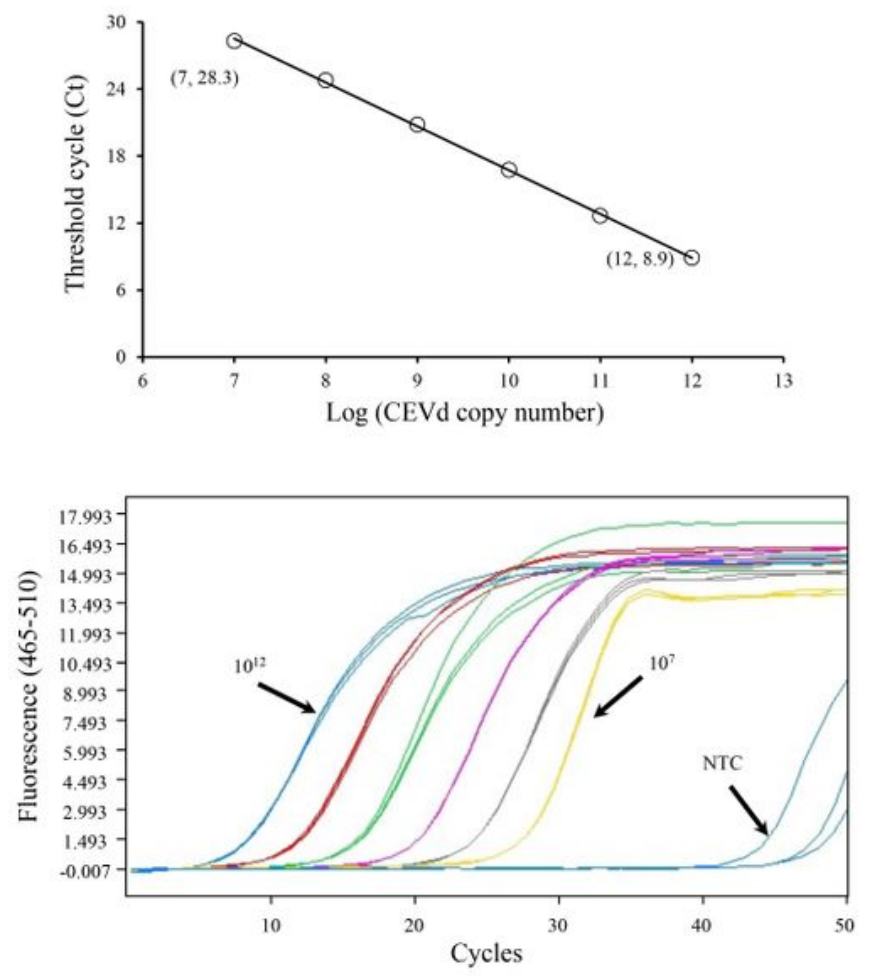

Figure 7B

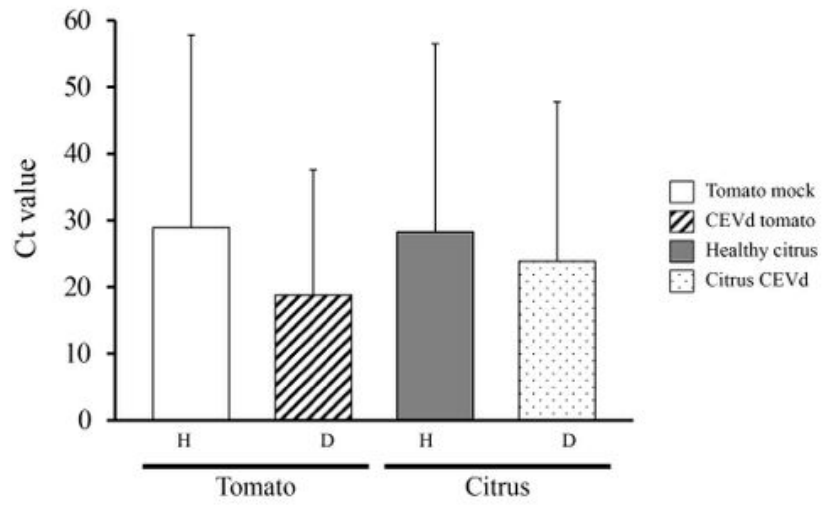

\section{Figure 7}

Detection of CEVd-infected samples by real-time RT-PCR. (A) Threshold cycle (Ct) and amplification curve established the standard curve for CEVd real-time RT-PCR analyses with ranging from 107 to 1012 copy numbers of CEVd transcripts. (B) Ct values were obtained from real-time RT-PCR amplification using 50 ng of tomato and citrus total RNAs. $\mathrm{H}$ : healthy plant; $\mathrm{D}$ : diseased CEVd-infected plant. Error bars indicated \pm standard deviation of the mean of three times of experimental replicate. 
A.

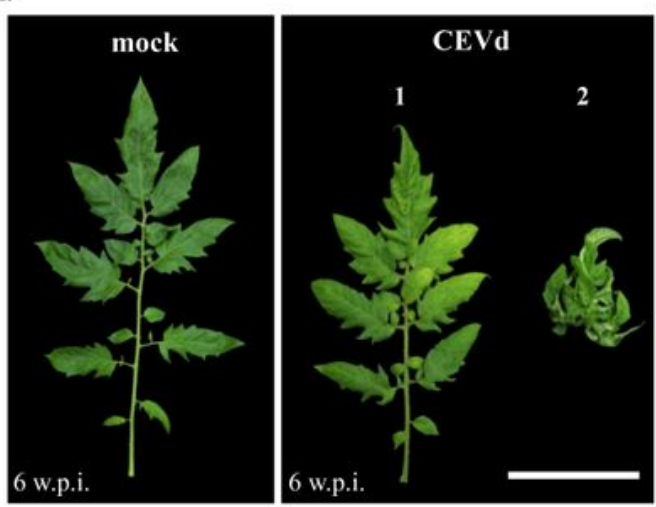

B.

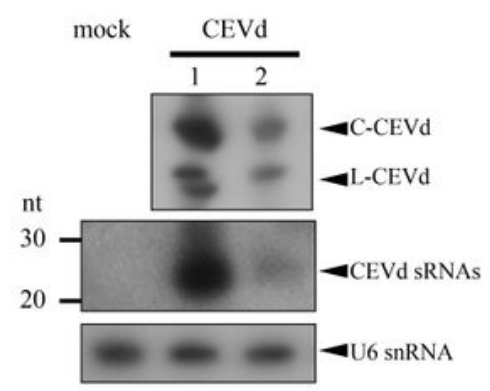

Figure $8 \mathrm{C} \& 8 \mathrm{D}$

C.

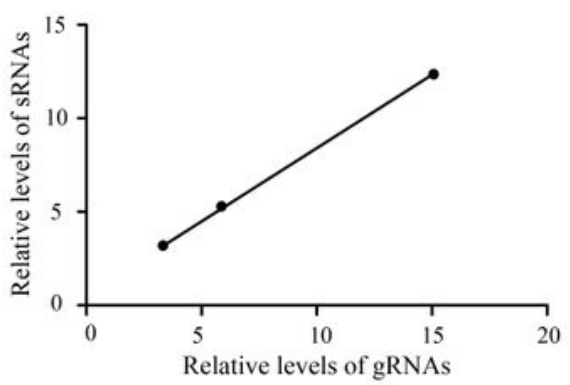

D.

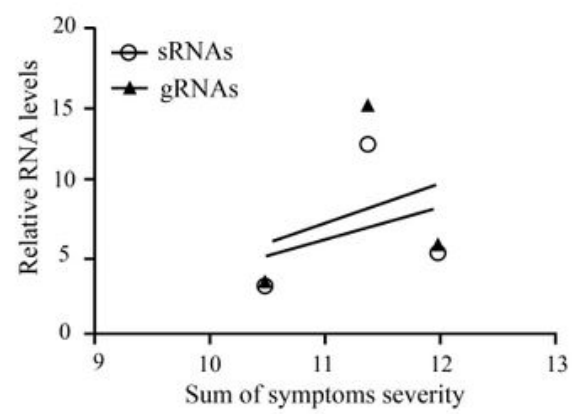

\section{Figure 8}

Symptom development on CEVd-infected Rutgers is associated with the levels of CEVd genomic RNA (gRNAs) and CEVd-derived small RNAs (sRNAs). (A) Varied degrees of CEVd-infected symptoms on Rutgers tomatoes. The photographs were taken at 6 w.p.i. Scale bar $=5 \mathrm{~cm}$. (B) CEVd viroid genomic RNA and small RNA were analyzed by denaturing northern blot. U6 snRNA was used as an internal control. (C) 
The relative expression levels between CEVd gRNAs and sRNAs. (D) The gRNAs and sRNAs of CEVd were plotted against index of symptom severity of the two CEVd-infected Rutgers samples.

\section{Supplementary Files}

This is a list of supplementary files associated with this preprint. Click to download.

- Fig.S1LinCHetal.pdf

- Fig.S2ALinCHetal.pdf 